\title{
Multimodal Transport System Coevolution Model Based on Synergetic Theory
}

\author{
Fenling Feng and Qingya Zhang \\ School of Traffic and Transportation Engineering, Central South University, Changsha 410075, China \\ Correspondence should be addressed to Fenling Feng; ffl0731@163.com
}

Received 17 July 2014; Revised 3 September 2014; Accepted 21 September 2014

Academic Editor: Wuhong Wang

Copyright ( 2015 F. Feng and Q. Zhang. This is an open access article distributed under the Creative Commons Attribution License, which permits unrestricted use, distribution, and reproduction in any medium, provided the original work is properly cited.

This study investigates multimodal transport system evolution law with the consideration of synergetic theory. Compared with previous studies, this paper focuses on understanding influencing factors of system collaborative development. In particular, we have applied a multimodal system order parameter model to obtain the order parameter. Based on order parameters, the coevolution equations of the multimodal transport system are constructed with consideration of cooperation and competitive relationship between the subsystems. We set out the multimodal system followed the coevolution law of the freight system and dominated by the combined effects of order parameter line length and freight density. The results show that the coordination effects between railway, road, and water subsystems are stronger than aviation subsystem; the railway system is the short plank of the system. Some functional implications from this study are also discussed. Finally the results indicate that expansion of railway system capacity and mutual cooperation within the subsystems are required to reach an optimal multimodal transport system.

\section{Introduction}

Multimodal transport combines the railway transport, water transport, road transport, aviation, and other traditional modes of transport. Multimodal transport has the potential to leverage advantages of various transport modes and enhance efficiency of transport. In recent years, multimodal transport has been developing rapidly because of its ability in time and transferring cost savings and enhancing transport organization.

Countries worldwide have implemented a series of policies to encourage the development of multimodal transport. In 1980, "Convention on International Multimodal Transport" was signed in Geneva, and the meaning of "multimodal" was determined. USA went through a series of laws to encourage the multimodal transport bill. European Union in 2006 proposed that combined transport was a term. In 2011, the EU Commission claimed "Roadmap to a single European transport area-towards a competitive and resource-efficient transport system" to further promote the development of sustainable transport and improve the service of intermodal transport chain. By 2014, the UK makes a budget of 200 million pounds on the investment in the strategic freight network of railway constructions. In recent years, China has also begun to focus on the development of a comprehensive transport system, to make the advantages of a variety of modes be one system. In 2009, the State Council put forward the "logistics industry restructuring and revitalization plan," in which "multimodal transport" was as the first key projects. In 2011, "to optimize the transport organization, innovative services, advance ticket one way, multimodal transport of goods" was clearly put forward. In 2013, The State Council revoked the Ministry of Railway and made into the Ministry of Railway, which is to improve the comprehensive transport system.

Researchers have been investigating multimodel transport from various aspects. van Nes [1], Kindred and Brooks [2], and Hoeks [3] have published a number of researches focusing on multimodal transport network planning, organizational management. Banomyong and Beresford [4] used Laos as an example, to explore the impact of multimodal transport mode and route of Laos selection factors and 
the key factors of multimodal transport management. T. Wang and G. Wang [5] established a virtual multimodal transport network model in China with considerations of low usage of multimodal transport and the lack of relevant decision support system. Bock [6] proposed a new real-time control method which uses the traffic hub and foreign service cooperation protocol considerations. Zhang et al. [7] and Feng et al. [8] analyzed the freight system and tried to find a model to find the laws of the system. Caraiani et al. [9] studied the need of multimodal transport business under the internationalized environment and identified the problems that needed to be addressed. Other researches are focused on multimodal system path selection, transport mode selection, and so forth.

In 1971, Haken first proposed the idea of "coordination"; with the idea discussed systematically, synergistic is formed. Now, synergistic includes synergies, servo principle, and the principle of self-organization and so on. The order parameter refers to the evolution of the system from none to some in the process of change. It affects the various elements of the system changed from one state to another state with collective collaborative behavior. And it can indicate a new parameter of structure formation, which is the dominant factor of modern management development [10]. In 1964, biologists Ehrlich and Raven first proposed the "coevolution." In the research of the evolution and the interaction between the enterprise and the environment, coevolution is applicable to the field of management science. Pan [11], Wang et al. [12], and Wang [13] studied the complex system coevolution mechanism. Feng and Wang [14] analyzed the railway network system with graph theory. In the aspect of freight system evolution, Ruzzenenti and Basosi [15] explored European multimodal transport energy efficiency evolution. Rail transport is one of the most common multimodal transport modes. Feng et al. [16] built a synergy evolutionary model of the collecting, distributing, and transporting system of railway heavy haul transport by introducing synergy-related concepts and applying the synergy evolutionary theory. He et al. [17] analyzed the model of road express transport system evolution.

To sum up, the researches of the scholars are mainly on multimodal transport planning, management, and sustainable development, and there is lack of multimodal system evolution researches. So grasping the multimodal transport system coevolution rules for decision making and planning of the multimodal transport system has important significance.

This paper investigates methods of multimodal transport systems planning focusing on coevolution. The evolutionary development of the freight transport system is discussed. It is to get that the multimodal transport system is the product of a certain stage of the freight transport system development. Through understanding the development of collaborative evolution, it can be clear that the current situation of each subsystem of the multimodal transport system and coordination coefficients and stimulation factors between its internal can be learned. In many factors, we can set the order parameter model to obtain the order parameter which controls and dominates the system. It can also clearly reflect the relationship between the transport ability and social needs of each subsystem.

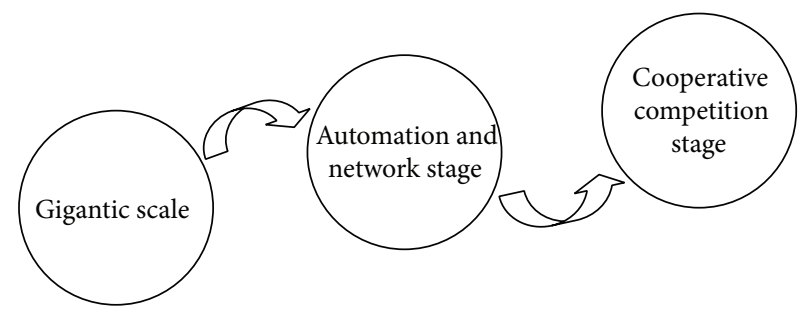

FIGURE 1: Level of multimodal transport system from the time dimension.

This paper contributes to the state-of-art knowledge in three aspects. One is the mathematical method which provides a comprehensive and objective model for multimodal transport system evolution. This method includes establishing coevolution equation and order parameter model. And the method has been applied to the multimodal transport system, which is also suitable for the various modes of the system. At last, this paper puts forward the two dimensions of time and space to analyze the freight transport system evolutionary development. We can get that the multimodal transport system is in the period of freight system progress when all subsystems are perfect. Finally, this paper utilizes China multimodal transport system as an example, and this coevolution model is calculated and analyzed.

\section{Problem Descriptions}

2.1. Hierarchical Development of Freight System Coevolution. The multimodal transport system is the transport mode with container carrier and is the product of a definite stage of freight system development. From the time dimension, the advance of the freight system experienced scale stage, automation and network stage, and cooperative competition stage (Figure 1). Scale stage refers to the coexistence of various modes of transport, solo mode of transport development in scale, but the subsystems are not perfect. Automation and network stage has modified the original freight site or new freight site with automatic transfer system, computer management system, transmission equipment, computer monitoring system, and packaging, circulation processing workshop. The freight station infrastructures are more seamless and can undertake various small, bulk-general cargo transports. The line can basically form into a network, and some subsystem has perfected. Collaborative competition stage refers to each subsystem that has been initially completed. Each mode of transport cooperation is mutual cooperation, mutual competition, and making the overall effectiveness of the freight system optimization.

From the space dimension, freight transport system development can be subdivided into the natural state, lower network state, and senior network state (Figure 2). In the early development of the freight system, transport modes and nodes are independent, with less communication between the various subsystems, such as a natural state. At the low-level network state, when the nodes and paths of each subsystem are gradually established, the freight system connects into the 


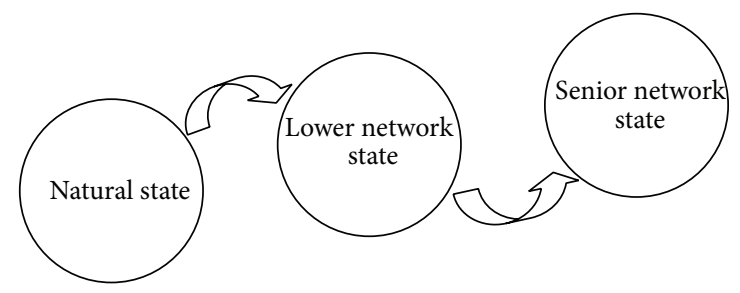

FIGURE 2: Level of multimodal transport system from the space dimension.

network, in order to facilitate the displacement transformation of goods.

At the senior network state, the subsystems will gradually improve and become perfect, to meet customer demand, such as quicker and more convenient transport, and freight network infrastructures are more perfect. The freight transport network improved from lower level to higher level network which has higher network speed.

van Nes proposed 3 forms of the multimodal system network type: linear type, grid type, and radial network (Figure 3), while the superposition of the multistage network lies in a network [1].

The type of system network is closely related to the characteristics of each subsystem and the form of the multimodal transport system. In a developed economy and wellestablished transport network, regional multimodal system network is usually of grid type; for example, in the water transport subsystem, the nodes usually lie offshore the river port with linear or radial network. For railway and road subsystem, the system networks are usually grid. But for aviation subsystem, the system network partially exists in linear or radial network.

The development process of the freight system is a spontaneous adjustment process from unstable stage to stable and collaborative stage. The multimodal transport system is in the cooperative competition stage, when each subsystem has been gradually improved, and system development has been in the senior network state, which is a combined transport mode.

2.2. Connotation of Cooperative Evolution of the Multimodal Transport System. The research goal of multimodal transport system coevolution is to study the competition and cooperation between subsystems: railway subsystem, road subsystem, water subsystem, and aviation subsystem. This method combines synergistic, coevolution theory, and mathematical statistics to investigate multimodal system coevolution. In order to meet consumer demand for the multimodal transport products, the operation mode of multimodal transport subsystem coordination is established, which can achieve the overall effect.

As the functions of subsystems in the intermediate system are closely linked, the functions of each subsystem will directly affect the other subsystems. If the ability is insufficient, it will lead to the fact that other subsystems cannot work with it, what is more, affecting the overall system synergy. With the evolutionary process study, it will enable each subsystem to do best to increase the overall efficiency of the system.

\section{Order Parameter Model of Multimodal System Coevolution}

3.1. Parameter Selection. Multimodal transport system is the product of collaborative competition stage of freight system progress. Hence there are both connections and differences in multimodal transport system coevolution. The parameter selection principle should include methodical, rationality, and validity in order to reflect the overall evolutionary characteristics of multimodal system.

Influencing factors of freight system development can be analyzed from 4 aspects: workforce level, fixed facilities, construction scale, and operation. Workforce level represents the number of employees and average salaries of workers. Fixed facilities include the length of line. Construction scale refers to the system development, including construction investment. Operation includes freight and freight turnover.

In order to represent the collaborative relationship and collaborative and competitive relationship of each subsystem in the multimodal transport system, we choose freight density to show multimodal transport network development and custom demand. Because of that, the development trend of the multimodal transport system is shown with an average transport distance.

Using the China multimodal transport system as an example, the parameter names of multimodal transport system are as shown in Table 1.

3.2. Model Solution. According to the paper written by Zhang and Feng [18], the order parameter model can consist of parameter selection by probe graph and model building, using Fourier functions to make the curve fitting of the freight system coevolution process and then using MATLAB to solve the absolute error and relative error of the model and the curve of the model calculation value and the real value.

Now the data of Chinese multimodal transport system in 1992-2011 is collected as follows in Table 2.

Freight density refers to the freight volume of a certain transport mode in a certain period time and section operating average every kilometer. The formula is

$$
\text { Freight density }=\frac{\text { Freight turnover }}{\text { Route length }} \text {. }
$$

Using the order parameter model, to the freight system, the relaxation coefficients of the system parameters are

$$
\begin{array}{lll}
\gamma_{1}=0.39010, & \gamma_{2}=0.1877, & \gamma_{3}=0.0037, \\
\gamma_{4}=0.0448, & \gamma_{5}=0.7846, & \gamma_{6}=0.1392 .
\end{array}
$$




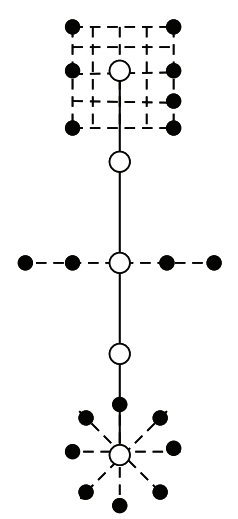

(a)

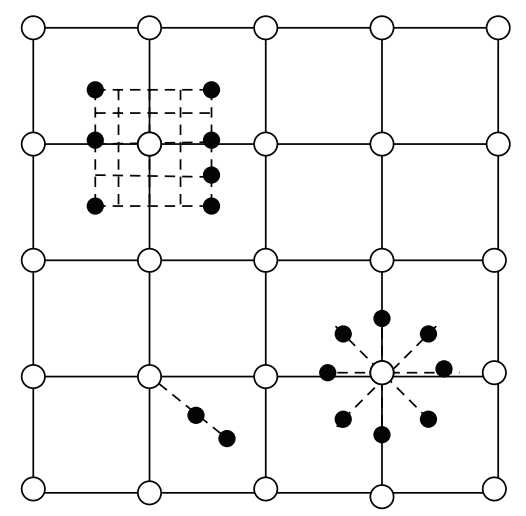

(b)

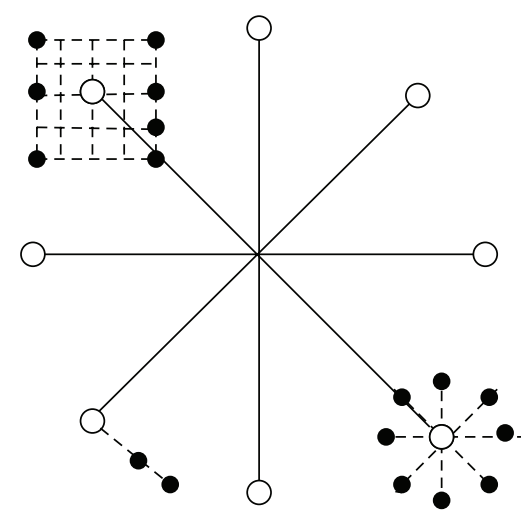

(c)

FIGURE 3: Examples of hierarchical networks superimposed on lower-level networks ((a) linear network, (b) grid network, and (c) radial network) [1].

TABLE 1: Multimodal transport system coevolution parameters.

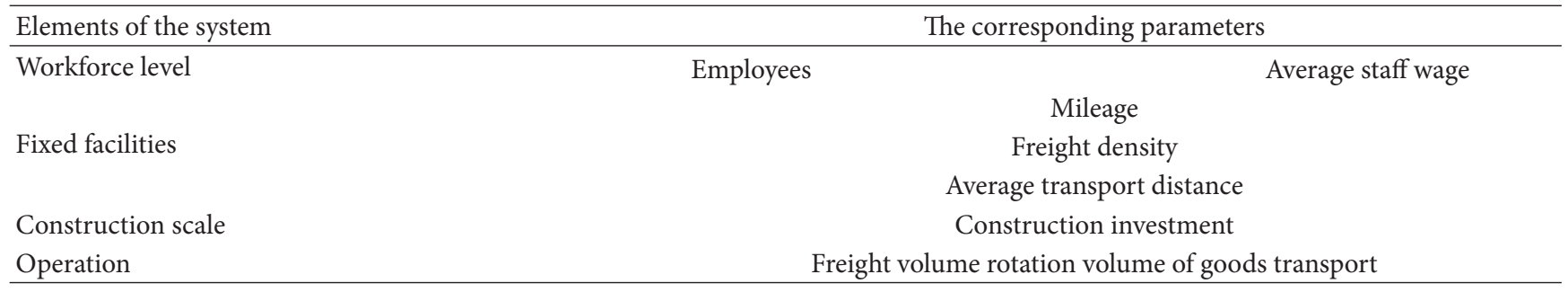

TABLE 2: Parameters of multimodal system coevolution.

\begin{tabular}{|c|c|c|c|c|c|c|c|c|}
\hline Year & $\begin{array}{c}\text { Number of } \\
\text { employees } \\
\text { (million) }\end{array}$ & $\begin{array}{l}\text { Average } \\
\text { wage } \\
\text { (Yuan) }\end{array}$ & $\begin{array}{c}\text { Mileage } \\
\text { (million km) }\end{array}$ & $\begin{array}{c}\text { Average } \\
\text { distance } \\
(\mathrm{km})\end{array}$ & $\begin{array}{c}\text { Construction } \\
\text { investment } \\
\text { (billion Yuan) }\end{array}$ & $\begin{array}{l}\text { Freight volume } \\
\text { (million tons) }\end{array}$ & $\begin{array}{l}\text { Rotation volume } \\
\text { (billion ton-km) }\end{array}$ & $\begin{array}{c}\text { Freight density } \\
\text { (million tons } \mathrm{km} / \mathrm{km} \text { ) }\end{array}$ \\
\hline 1992 & 895 & 3114 & 206.11 & 279 & 45.758 & 1045899 & 29218 & 1418 \\
\hline 1993 & 916 & 4273 & 221.26 & 275 & 90.124 & 1115771 & 30525 & 1380 \\
\hline 1994 & 921 & 5690 & 232.51 & 283 & 137.294 & 1180273 & 33275 & 1431 \\
\hline 1995 & 826 & 6948 & 245.63 & 291 & 158.753 & 1234810 & 35909 & 1462 \\
\hline 1996 & 835 & 7870 & 252.8 & 282 & 184.462 & 1298312 & 36590 & 1447 \\
\hline 1997 & 824 & 8600 & 282.72 & 300 & 219.745 & 1278087 & 38385 & 1358 \\
\hline 1998 & 701 & 9808 & 296.1 & 301 & 325.219 & 1267200 & 40568 & 1370 \\
\hline 1999 & 682 & 10991 & 305.78 & 314 & 342.928 & 1292650 & 40568 & 1327 \\
\hline 2000 & 659 & 12319 & 309.36 & 326 & 364.194 & 1358124 & 44321 & 1433 \\
\hline 2001 & 629 & 14167 & 344.32 & 340 & 411.643 & 1401177 & 47710 & 1386 \\
\hline 2002 & 613 & 16044 & 359.64 & 342 & 439.398 & 1482737 & 50686 & 1409 \\
\hline 2003 & 636.5 & 15753 & 375.63 & 344 & 628.94 & 1561422 & 53859 & 1434 \\
\hline 2004 & 631.8 & 18071 & 411.78 & 407 & 764.62 & 1706412 & 69445 & 1686 \\
\hline 2005 & 613.9 & 18200 & 554.24 & 431 & 961.40 & 1862066 & 80258 & 1448 \\
\hline 2006 & 612.7 & 20856 & 577.1 & 436 & 1213.81 & 2037892 & 88952 & 1541 \\
\hline 2007 & 623.1 & 24721 & 623.65 & 446 & 1415.40 & 2275822 & 101419 & 1626 \\
\hline 2008 & 627.3 & 28898 & 651.31 & 427 & 1702.44 & 2585937 & 110300 & 1694 \\
\hline 2009 & 634.4 & 32244 & 654.92 & 432 & 2497.47 & 2825222 & 122133 & 1865 \\
\hline 2010 & 631.1 & 36539 & 714.14 & 438 & 3007.45 & 3241807 & 141837 & 1986 \\
\hline 2011 & 662.8 & 47078 & 798.31 & 431 & 2829.17 & 3696961 & 159324 & 1996 \\
\hline
\end{tabular}



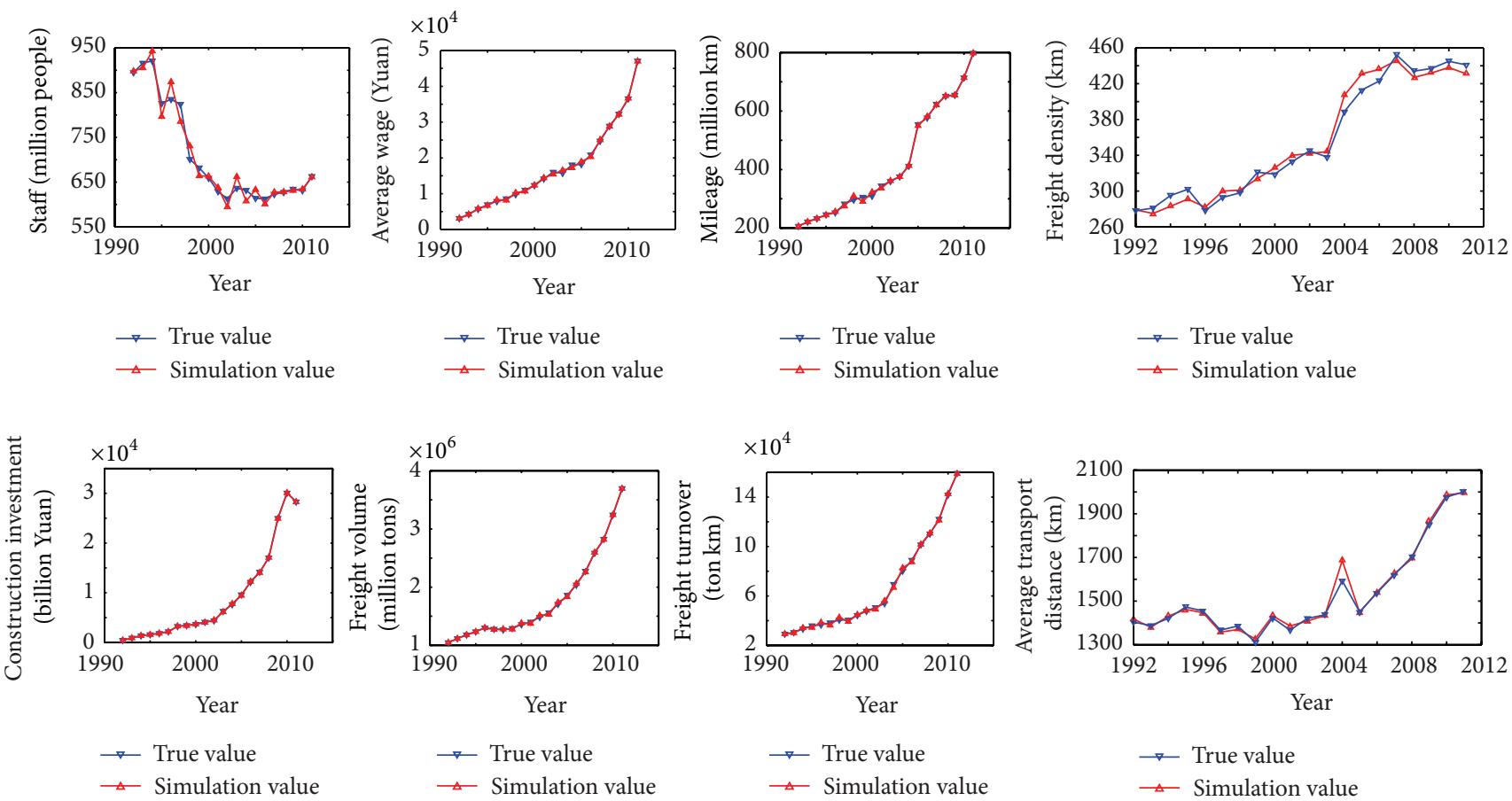

FIGURE 4: Simulation results of multimodal transport system coevolution.

In the multimodal transport system, the relaxation coefficients of the system parameters are

$$
\begin{gathered}
\gamma_{1}=0.4261, \quad \gamma_{2}=0.2312, \quad \gamma_{3}=0.0946, \\
\gamma_{4}=0.0193, \quad \gamma_{5}=0.1028, \quad \gamma_{6}=0.9431, \\
\gamma_{7}=0.1792, \quad \gamma_{8}=0.0057 .
\end{gathered}
$$

Compared with the size of each parameter relaxation coefficient, we can obtain that $\gamma_{8}$ freight density is the minimum and $\gamma_{3}$ mileage comes second. Then we verify the parameters of the simulation values, the curve fitting of simulation value and true value as shown in Figure 4.

From Figure 4, the parameters of the simulation results basically conform to those of real value. According to Haken's synergistic servo theory, the multimodal transport system density is the order parameter of the system. Multimodal transport system is also followed by mileage, which is the order parameter of freight system. Namely, freight density and mileage are the order parameters of dual control of the system.

Mileage is the direct manifestation of freight infrastructure construction. While the multimodal transport system density can reflect the freight transport demand of social areas and the rush hour of transport lines, they can be able to balance operation and planning, construction, and transformation and to be an important basis for the study of transport network planning. For the indicators, freight density is jointly decided by the freight turnover and operating mileage Only when the traffic facilities meet with market demand, the system develops just as it needs, which tends to be coordinated progress with more efficiency.

However, for a complex system, in the dominant double order parameters of freight density and mileage freight, with other interaction parameters, the coevolution of multimodal transport system goes on.

\section{Model of Multimodal System Coevolution}

\subsection{Assumptions}

Hypothesis 1. It is assumed that in the particular stage of development the inherent growth rate of the transport capacity and freight volume are relatively stable and can be represented by a constant.

Hypothesis 2. The freight transport capacity and freight demand are a continuous and differentiable function of time.

Hypothesis 3. The growth of subsystems capacity and freight volume are consistent with the logistic growth law.

Hypothesis 4. The synergistic effect of a subsystem on another subsystem is commensurate with the ability of the former subsystem.

\subsection{Notations. See Table 3.}

4.3. Mathematical Model. The supply capacity of railway transport $s_{1}$ is decided on the railway system demand of 
TABLE 3: Symbols instructions of multimodal transport system coevolution.

\begin{tabular}{ll}
\hline Notations & Instructions \\
\hline$n_{i}(i=1,2,3,4)$ & $\begin{array}{l}\text { The quantity demanded of subsystems (railway, road, water transport, and aviation) } \\
\text { The demand on the time differential of subsystems of railway, road, water, and } \\
\text { aviation }\end{array}$ \\
$\dot{n}_{i}(i=1,2,3,4)$ & $\begin{array}{l}\text { The demand growth rate of subsystems of railway, road, water, and aviation } \\
\gamma_{i}(i=1,2,3,4)\end{array}$ \\
$N_{i}(i=1,2,3,4)$ & $\begin{array}{l}\text { Maximum demand of subsystems of railway, road, water, and aviation } \\
\text { Transport capacity of subsystems of railway, road, water, and aviation }\end{array}$ \\
$s_{i}(i=1,2,3,4)$ & $\begin{array}{l}\text { In no other system capacity under the influence, the maximum transport capacity } \\
\text { by its own resource constraints can reach the railway, road, water, and aviation } \\
\text { subsystems. }\end{array}$ \\
\hline$S_{i}(i=1,2,3,4)$ &
\end{tabular}

railway system $N_{1}$, the changes of $\dot{n_{1}}$, and its own growth rate $\gamma_{1}$; that is,

$$
\frac{d n_{1}}{d t}=\gamma_{1} n_{1}\left(1-\frac{n_{1}}{N_{1}}+\alpha_{1} \frac{s_{1}}{S_{1}}\right)
$$

In formula (4), $\theta_{i}(i=1,2,3,4)$ expressed the railway system transport capacity. Due to its growth $\beta_{i}(i=1,2,3,4)$ reflects the stimulating factor of cargo subsystem increased by unit to transport capacity of subsystem, $\beta_{i}>0$.

Changes in transport capacity of railway system effect rate are represented as $\dot{s_{1}}$, the synergistic effect rate is $\theta_{1}$, the synergistic effects are $s_{2}, s_{3}$, and the stimulatory effect is $n_{1}$. Then, the evolution equations for railway system transport capacity $s_{1}$ are

$$
\frac{d s_{1}}{d t}=\theta_{1} s_{1}\left(1-\frac{s_{1}}{S_{1}+\mu_{21} s_{2}+\mu_{31} s_{3}+\mu_{41} s_{4}}+\beta_{1} \frac{n_{1}}{N_{1}}\right) .
$$

Similarly, under the circumstances, four subsystems in the multimodal transport system are coordinated developing. With the mutual influence of freight transportation demand and freight transport capacity, we can find the coevolution equations of other 3 subsystems-road subsystem, water subsystem, and aviation subsystem.

In the research, with the introduction of random fluctuations of the deterministic model, we can get the Langevin equation of multimodal system coevolution:

$$
\begin{aligned}
& \frac{d n_{1}}{d t}=\gamma_{1} n_{1}\left(1-\frac{n_{1}}{N_{1}}+\alpha_{1} \frac{s_{1}}{S_{1}}\right)+f\left(n_{1}\right) \frac{d w_{1}}{d t}, \\
& \frac{d n_{2}}{d t}=\gamma_{2} n_{2}\left(1-\frac{n_{2}}{N_{2}}+\alpha_{2} \frac{s_{2}}{S_{2}}\right)+f_{2}\left(n_{2}\right) \frac{d w_{2}}{d t}, \\
& \frac{d n_{3}}{d t}=\gamma_{3} n_{3}\left(1-\frac{n_{3}}{N_{3}}+\alpha_{3} \frac{s_{3}}{S_{3}}\right)+f_{3}\left(n_{3}\right) \frac{d w_{3}}{d t}, \\
& \frac{d n_{4}}{d t}=\gamma_{4} n_{4}\left(1-\frac{n_{4}}{N_{4}}+\alpha_{4} \frac{s_{4}}{S_{4}}\right)+f_{4}\left(n_{4}\right) \frac{d w_{4}}{d t},
\end{aligned}
$$

$$
\begin{aligned}
& \frac{d s_{1}}{d t}=\theta_{1} s_{1}\left(1-\frac{s_{1}}{S_{1}+\mu_{21} s_{2}+\mu_{31} s_{3}+\mu_{41} s_{4}}+\beta_{1} \frac{n_{1}}{N_{1}}\right) \\
& +F_{1}\left(N_{1}\right) \frac{d W_{1}}{d t} \\
& \frac{d s_{2}}{d t}=\theta_{2} s_{2}\left(1-\frac{s_{2}}{S_{2}+\mu_{12} s_{1}+\mu_{32} s_{3}+\mu_{42} s_{4}}+\beta_{2} \frac{n_{2}}{N_{2}}\right) \\
& +F_{2}\left(N_{2}\right) \frac{d W_{2}}{d t} \\
& \frac{d s_{3}}{d t}=\theta_{3} s_{3}\left(1-\frac{s_{3}}{s_{3}+\mu_{13} s_{1}+\mu_{23} s_{2}+\mu_{43} s_{4}}+\beta_{3} \frac{n_{3}}{N_{3}}\right) \\
& +F_{3}\left(N_{3}\right) \frac{d W_{3}}{d t}, \\
& \frac{d s_{4}}{d t}=\theta_{4} s_{4}\left(1-\frac{s_{4}}{s_{4}+\mu_{14} s_{1}+\mu_{24} s_{2}+\mu_{34} s_{3}}+\beta_{4} \frac{n_{4}}{N_{4}}\right) \\
& +F_{4}\left(N_{4}\right) \frac{d W_{4}}{d t} \text {. }
\end{aligned}
$$

Functions $f_{1}\left(n_{1}\right), f_{2}\left(n_{2}\right), f_{3}\left(n_{3}\right), f_{4}\left(n_{4}\right), F_{1}\left(N_{1}\right), F_{2}\left(N_{2}\right)$, $F_{3}\left(N_{3}\right)$, and $F_{4}\left(N_{4}\right)$ are diffusion, and $w_{1}, w_{2}, w_{3}, w_{4}, W_{1}, W_{2}$, $W_{3}$, and $W_{4}$ are standard Brownian movements.

\section{Analysis of Multimodal Transport System Coevolution in China}

We implemented the methodology to Chinese multimodal transport system. Container freight volumes of railway, road, water, and aviation subsystems are based on historical data between 1999 and 2012 (Table 4).

Replacing its growth rate with average growth and the system growth rate of railway, road, water, and aviation subsystems we calculate the average growth rate based on historical data and use them in our model.

$$
\begin{aligned}
\theta_{1}=0.05115, \quad \theta_{2} & =0.18599, \quad \theta_{3}=0.10230, \\
\theta_{4} & =0.15037 .
\end{aligned}
$$

Definition of the attraction coefficient of the railway system is the changes in social freight volume and turnover 
TABLE 4: Container freight volumes of subsystems and social system.

\begin{tabular}{cccccc}
\hline \multirow{2}{*}{ Year } & \multicolumn{5}{c}{ Container freight volumes (million tons) } \\
& Railway & Road & Water & Aviation & Social \\
\hline 1999 & 0.38 & 1.09 & 0.89 & 0.02 & 2.39 \\
2000 & 0.45 & 1.29 & 1.10 & 0.02 & 2.86 \\
2001 & 0.47 & 1.55 & 1.24 & 0.02 & 3.28 \\
2002 & 0.59 & 1.68 & 1.50 & 0.02 & 3.80 \\
2003 & 0.60 & 2.37 & 1.59 & 0.03 & 4.58 \\
2004 & 0.56 & 2.76 & 2.20 & 0.03 & 5.55 \\
2005 & 0.65 & 3.67 & 2.58 & 0.03 & 6.93 \\
2006 & 0.71 & 5.32 & 3.34 & 0.04 & 9.41 \\
2007 & 0.67 & 7.14 & 5.48 & 0.04 & 13.33 \\
2008 & 0.69 & 5.96 & 3.46 & 0.04 & 10.16 \\
2009 & 0.82 & 6.63 & 4.23 & 0.06 & 11.74 \\
2010 & 0.92 & 7.44 & 5.18 & 0.06 & 13.80 \\
2011 & 0.91 & 8.27 & 5.48 & 0.05 & 14.71 \\
2012 & 0.38 & 1.09 & 0.89 & 0.02 & 2.39 \\
\hline
\end{tabular}

volume of the railway subsystem, the same method to define the attractive coefficients of other subsystems. Stimulating factors of freight transport capacity development coefficient (the railway transport capacity increase factor caused by freight demand increasing stimulation/rate), the stimulating factor is defined by the changes with multimodal system turnover and social turnover caused by the multimodal transport system to railway subsystem, the same method to define the stimulating factors of other subsystems. The values of attractive coefficients and stimulating factors are listed as Table 5.

The results indicate four subsystems of turnover is smooth approximation fit. The best fitting model is obtained when $S_{1}=1.00, S_{2}=9.50, S_{3}=6.50$, and $S_{4}=0.06$. The best fitting model is selected based on goodness of fit criteria and their values are shown below:

$$
\begin{aligned}
R_{1}^{2}=0.9993, \quad R_{2}^{2} & =0.96231, \quad R_{3}^{2}=0.97159, \\
R_{4}^{2} & =0.97159 .
\end{aligned}
$$

Setting each subsystem of freight turnover in 2011 as the initial values,

$$
\begin{array}{ll}
s_{1}^{0}=0.88 \text { Ton } \mathrm{km} / \text { year }, & s_{2}^{0}=9.13 \text { Ton } \mathrm{km} / \text { year }, \\
s_{3}^{0}=6.34 \text { Ton } \mathrm{km} / \text { year }, & s_{4}^{0}=0.058 \text { Ton } \mathrm{km} / \text { year. }
\end{array}
$$

The coefficient factors $\mu$ can be divided into low coordination, in the collaborative, and high coordination to simulate. The coefficient factors $\mu_{21}, \mu_{31}, \mu_{41}, \mu_{12}, \mu_{32}, \mu_{42}, \mu_{13}, \mu_{23}, \mu_{43}$, $\mu_{14}, \mu_{24}$, and $\mu_{34}$ can be listed as Table 6 .

By four-order Runge Kutta method for solving the model, the simulation results are shown in Figures 5, 6, 7, and 8.

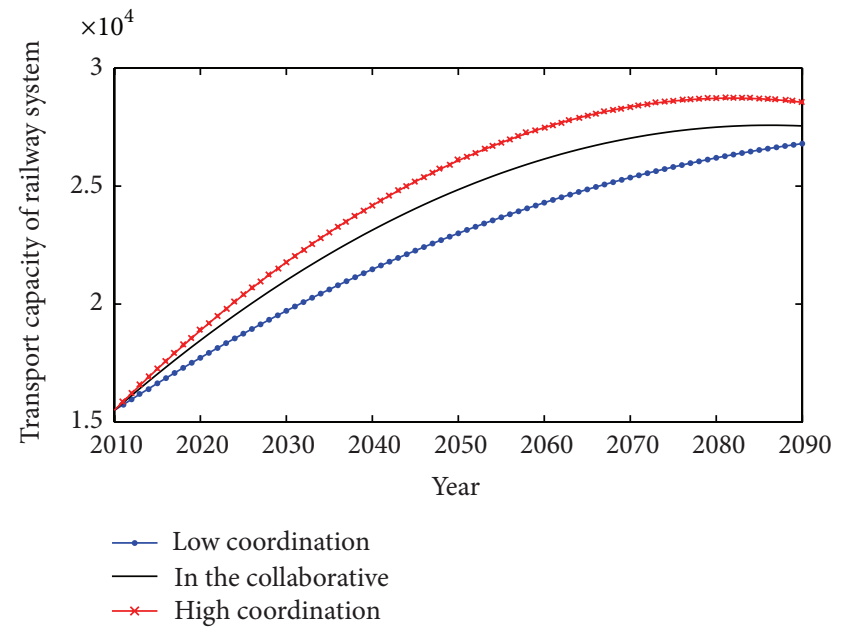

FIGURE 5: Railway and multimodal capacity.

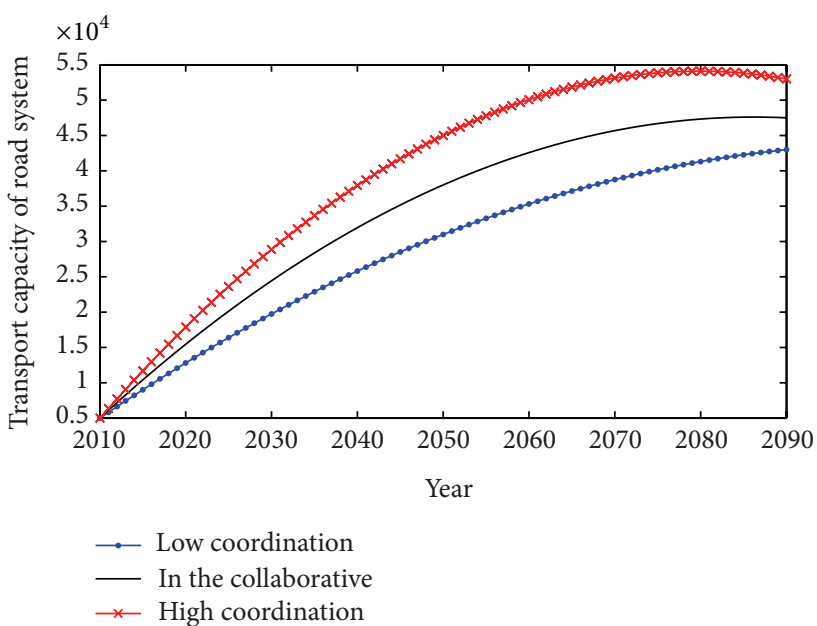

FIGURE 6: Road and multimodal capacity.

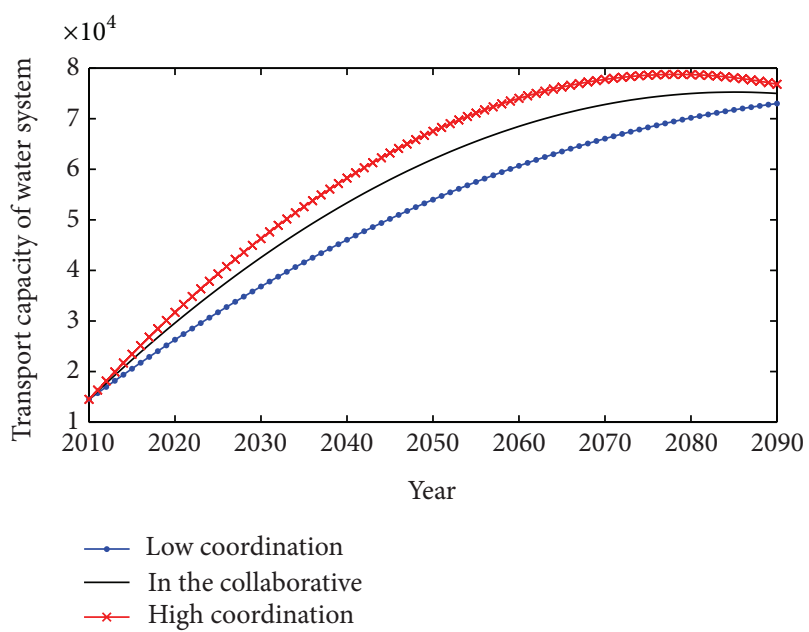

FIGURE 7: Water and multimodal capacity. 
TABLE 5: Attractive coefficients and stimulating factors.

\begin{tabular}{lcccccccc}
\hline Parameter & $\alpha_{1}$ & $\alpha_{2}$ & $\alpha_{3}$ & $\alpha_{4}$ & $\beta_{1}$ & $\beta_{2}$ & $\beta_{3}$ \\
\hline Value & 0.2944 & 0.2516 & 0.4430 & 0.0007 & 0.2862 & 0.2611 & 0.4520 & 0.0008 \\
\hline
\end{tabular}

TABLE 6: Multimodal transport system synergistic coefficient factors.

\begin{tabular}{|c|c|c|c|c|c|c|}
\hline Parameter & $\mu_{21}$ & $\mu_{31}$ & $\mu_{41}$ & $\mu_{12}$ & $\mu_{32}$ & $\mu_{42}$ \\
\hline Low coordination & 0.0022 & 0.0024 & 0.0021 & 0.0015 & 0.0026 & 0.0023 \\
\hline In the collaborative & 0.0032 & 0.0034 & 0.0031 & 0.0025 & 0.0036 & 0.0033 \\
\hline High coordination & 0.0042 & 0.0044 & 0.0041 & 0.0035 & 0.0046 & 0.0043 \\
\hline Parameter & $\mu_{13}$ & $\mu_{23}$ & $\mu_{43}$ & $\mu_{14}$ & $\mu_{24}$ & $\mu_{34}$ \\
\hline Low coordination & 0.0022 & 0.0018 & 0.0024 & 0.0029 & 0.0021 & 0.0027 \\
\hline In the collaborative & 0.0032 & 0.0028 & 0.0034 & 0.0039 & 0.0031 & 0.0037 \\
\hline High coordination & 0.0042 & 0.0038 & 0.0044 & 0.0049 & 0.0041 & 0.0047 \\
\hline
\end{tabular}

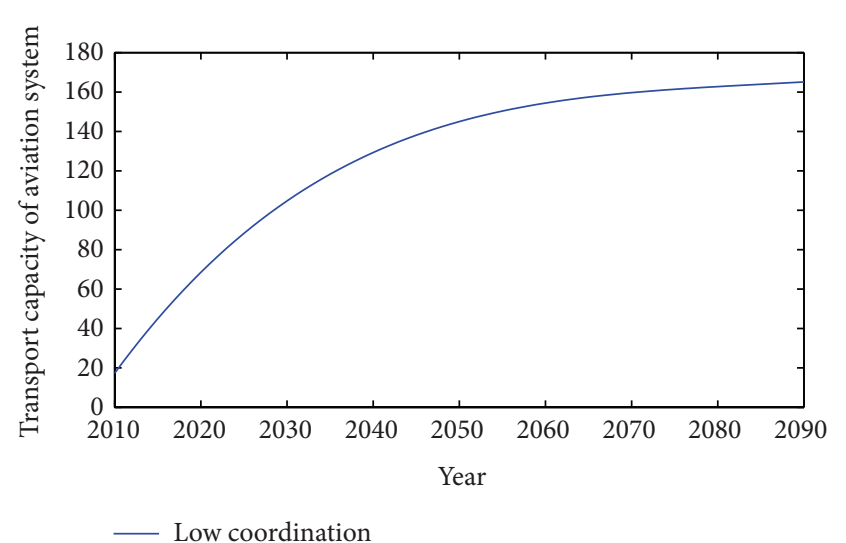

FIGURE 8: Aviation and multimodal capacity.

Using the iterative method for solving formula (6), the cooperative and coefficient equilibrium of the system could be achieved as shown below.

Low coordination:

$$
\left(s_{1}^{*}, s_{2}^{*}, s_{3}^{*}, s_{4}^{*}\right)=(1.02,9.78,6.53,0.053) .
$$

In the collaborative:

$$
\left(s_{1}^{*}, s_{2}^{*}, s_{3}^{*}, s_{4}^{*}\right)=(1.05,9.60,6.59,0.056) .
$$

High coordination:

$$
\left(s_{1}^{*}, s_{2}^{*}, s_{3}^{*}, s_{4}^{*}\right)=(1.08,9.66,6.61,0.058) .
$$

As shown from Figures 2, 3, 4, and 5, coordination coefficients increase, and the equilibrium points of transport capacity of 4 subsystems and multimodal transport system reach the greater one. The equilibrium point is independent of the final collaborative and multimodal transport system coefficient. The railway subsystem, road subsystem, and water subsystem, respectively, have strong synergism to multimodal transport system. The synergism of the aviation subsystem of the multimodal transport system is one order of magnitude lower than the synergistic effect of the other three subsystems.
The different coordination coefficient and the equilibrium point are calculated into

$$
A=\left.\left[\begin{array}{lll}
f_{x_{1}} & f_{x_{2}} & f_{x_{3}} \\
g_{x_{1}} & g_{x_{2}} & g_{x_{3}} \\
h_{x_{1}} & h_{x_{2}} & h_{x_{3}}
\end{array}\right]\right|_{P_{0}\left(x_{1}^{0}, x_{2}^{0}, x_{3}^{0}\right)}
$$

Among them $f_{x_{1}}, f_{x_{2}}, f_{x_{3}}, g_{x_{1}}, g_{x_{2}}, g_{x_{3}}, h_{x_{1}}, h_{x_{2}}, h_{x_{3}}$ can be calculated by

$$
\begin{aligned}
\frac{d x_{1}(t)}{d t}= & f_{x_{1}}\left(x_{1}^{0}, x_{2}^{0}, x_{3}^{0}\right)\left(x_{1}-x_{1}^{0}\right) \\
& +f_{x_{2}}\left(x_{1}^{0}, x_{2}^{0}, x_{3}^{0}\right)\left(x_{2}-x_{2}^{0}\right) \\
& +f_{x_{3}}\left(x_{1}^{0}, x_{2}^{0}, x_{3}^{0}\right)\left(x_{3}-x_{3}^{0}\right), \\
\frac{d x_{2}(t)}{d t}= & g_{x_{1}}\left(x_{1}^{0}, x_{2}^{0}, x_{3}^{0}\right)\left(x_{1}-x_{1}^{0}\right) \\
& +g_{x_{2}}\left(x_{1}^{0}, x_{2}^{0}, x_{3}^{0}\right)\left(x_{2}-x_{2}^{0}\right) \\
& +g_{x_{3}}\left(x_{1}^{0}, x_{2}^{0}, x_{3}^{0}\right)\left(x_{3}-x_{3}^{0}\right), \\
\frac{d x_{3}(t)}{d t}= & h_{x_{1}}\left(x_{1}^{0}, x_{2}^{0}, x_{3}^{0}\right)\left(x_{1}-x_{1}^{0}\right) \\
& +h_{x_{2}}\left(x_{1}^{0}, x_{2}^{0}, x_{3}^{0}\right)\left(x_{2}-x_{2}^{0}\right) \\
& +h_{x_{3}}\left(x_{1}^{0}, x_{2}^{0}, x_{3}^{0}\right)\left(x_{3}-x_{3}^{0}\right) .
\end{aligned}
$$

The calculated feature values of the model are as follows. Low coordination:

$$
\left(\lambda_{1}, \lambda_{2}, \lambda_{3}\right)=(-0.01245,-0.00587,-0.00145) .
$$

In the collaborative:

$$
\left(\lambda_{1}, \lambda_{2}, \lambda_{3}\right)=(-0.02431,-0.00246,-0.00453) \text {. }
$$

High coordination:

$$
\left(\lambda_{1}, \lambda_{2}, \lambda_{3}\right)=(-0.00345,-0.00671,-0.00345) \text {. }
$$




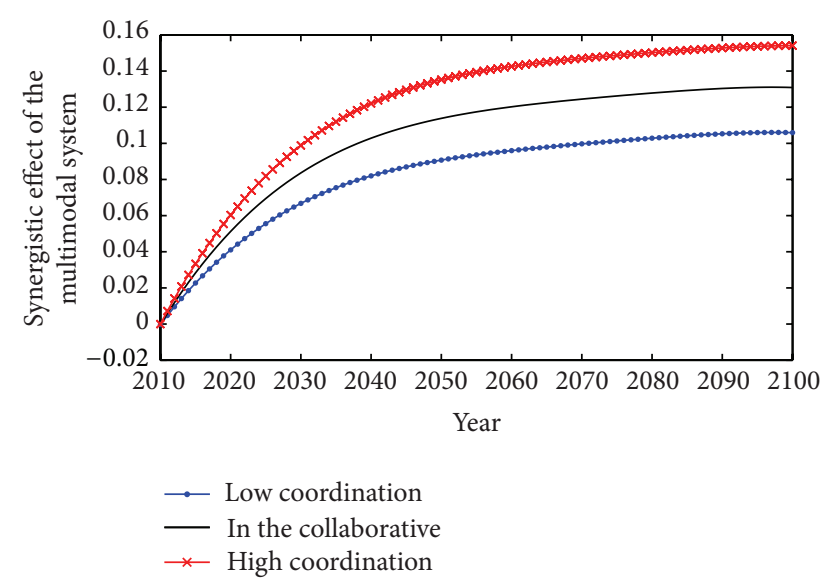

Figure 9: Effects of multimodal system collaborative evolution under cooperative coefficients.

According to the balance point and stability of threeorder differential equation, the characteristics of coefficient matrix A in different growth rate of the value are negative; finally the equilibrium point of the system is stable. When the system developed to this stage, multimodal transport capacity reached the speed of its development maximum, and the acceleration is zero. Meanwhile, the utilization maximizes, and the development reaches the peak. Then, with the limited resources, the development speed of the system gradually reduces and finally reaches a stable equilibrium.

Figure 9 is created based on the data from Table 4. Figure 9 explains in a given three kinds conditions of synergistic coefficients the multimodal system development tendency in the future. The system process tends to separate levels of multimodal transport system coevolution. Under high coordination, the coefficient is greater than low coordination and in the collaborative. The coevolution coordination degree effect of multimodal transport system is stronger, and the level of subsystems coevolution is more stable. The strengthening of coordination level between systems will maintain a sharp synergistic effect, which also verifies the rationality of the model.

From 2000, railway container market share decreased year by year. In recent years, railway container market share is only about $7 \%$ of the shared container market, and in 2013 the railway container transport volume is only 0.88 million tons, down $4.5 \%$ year-on-year, accounting for only $6 \%$ of social container volume. While the coefficient of railway subsystem is strong, whose transport capacity is far more than its freight volume, the railway subsystem is the control of short board for the collaborative development of the multimodal transport system. We should strengthen the transport container category marketing of railway subsystem and strengthen the link of the railway, road water, and aviation subsystems. We should release the railway transport capacity, to make the multimodal transport system coordination progress. And it is only strengthening the coordination level between systems; that is, the system will maintain the sharp synergistic effect. It further proved the rationality of this model.

\section{Conclusions}

Multimodal transport is a freight transport mode featured with high efficiency and high potency. It is a systematic combination of railway, road, and water transport, aviation, and other traditional transport modes that can take advantages of each individual transport mode and achieve higher efficiency. This paper explores the collaborative development structure of the multimodal transport system. In addition, combined with the structure of multimodal system coordination progress, the connotation of the multimodal transport system is discussed. Using the system order parameter model, freight density and mileage are derived as the order parameters of the multimodal transport system. With objective as maximizing capacity of multimodal transport system, both cooperation and competition between four subsystems are considered. Based on that, we built the coevolution equation of multimodal transport system.

The results show that (1) the coevolution law of the multimodal transport system is regulated by the law of the freight system under double order parameters: freight density and mileage. (2) When synergistic coefficient is increasing, the transport ability of railway, road, and water subsystems of the multimodal transport system is increasing as well with the strongest effects of subsystems interaction between road subsystem and railway subsystem. (3) Synergistic effect differs between subsystems. (4) The railway subsystem is the control of short board for the collaborative development of the multimodal transport system.

We should further strengthen the synergistic effect between factors. This paper can also be discussed with other mathematical theories, such as bifurcation theory, catastrophe theory, and synergistic.

\section{Conflict of Interests}

The authors declare that there is no conflict of interests regarding the publication of this paper.

\section{Acknowledgment}

This work was supported by the Fundamental Research Funds for the Central Universities of Central South University (no. 2013zzts210), the Fundamental Research Funds for the Central Universities (no. 2010QZZD021), and the Ministry of Railway Science and Technology Research Development Program (no. 2013X008-A).

\section{References}

[1] R. van Nes, Design of Multimodal Transport Networks: A Hierarchical Approach, DUP Science, Delft, The Netherlands, 2002.

[2] H. M. Kindred and M. R. Brooks, Multimodal Transport Rules, Kluwer Law International, The Hague, The Netherlands, 1997.

[3] M. Hoeks, Multimodal Transport Law, Proefschriftmaken.nl, 'sHertogenbosch, Netherlands, 2009.

[4] R. Banomyong and A. K. C. Beresford, Multimodal Transport Corridors in South East Asia: A Case Study Approach, University of Wales, Wales, UK, 2000. 
[5] T. Wang and G. Wang, "A combined optimization model for transportation modes of multimodal transport," Engineering Science, vol. 7, no. 10, pp. 46-50, 2005.

[6] S. Bock, "Real-time control of freight forwarder transportation networks by integrating multimodal transport chains," European Journal of Operational Research, vol. 200, no. 3, pp. 733746, 2010.

[7] J. Zhang, F. Liao, T. Arentze, and H. Timmermans, "A multimodal transport network model for advanced traveler information systems," Procedia Computer Science, vol. 5, pp. 912-919, 2011.

[8] F. Feng, L. Yang, and D. Lan, "Order-parameter model for synergetic theory-based railway freight system and evolution in China," Promet-Traffic \& Transportation, vol. 25, no. 3, pp. 195207, 2013.

[9] G. Caraiani, V. Potecea, and G. Surdu, "Multimodal transports, in the business internationalization context," Metalurgia International, vol. 18, no. 1, pp. 199-203, 2013.

[10] H. Haken, Synergetics: Nature and Secret, Shanghai Translating Press, Shanghai, China, 2001.

[11] A. Pan, "Modeling emerging behavior of firm's strategy in organizational change," Chinese Journal of Management Science, vol. 16, pp. 643-647, 2008 (Chinese).

[12] W. Wang, W. Zhang, H. Guo, H. Bubb, and K. Ikeuchi, "A safety-based approaching behavioural model with various driving characteristics," Transportation Research C: Emerging Technologies, vol. 19, no. 6, pp. 1202-1214, 2011.

[13] W.-H. Wang, "Driving behavior shaping model in road traffic system," Journal of Beijing Institute of Technology: English Edition, vol. 10, no. 3, pp. 331-335, 2001.

[14] F. Feng and L. Wang, "Robustness measure of China's railway network topology using relative entropy," Discrete Dynamics in Nature and Society, vol. 2013, Article ID 391709, 8 pages, 2013.

[15] F. Ruzzenenti and R. Basosi, "Evaluation of the energy efficiency evolution in the European road freight transport sector," Energy Policy, vol. 37, no. 10, pp. 4079-4085, 2009.

[16] F. Feng, D. Lan, and L. Yang, "Analysis on the synergy evolutionary development of the collecting, distributing, and transporting system of railway heavy haul transportation," Discrete Dynamics in Nature and Society, vol. 2012, Article ID 329120, 22 pages, 2012.

[17] J. He, W.-D. Yang, X.-H. Li, W. Hang, and H.-J. Mao, "Evolution mechanism of highway express freight transportation system based on dissipation structure theory," China Journal of Highway and Transport, vol. 20, no. 2, pp. 120-126, 2007.

[18] Q. Zhang and F. Feng, "Coevolutionary mechanism of freight transport system in China based on order parameter," in Proceedings of the 14th COTA International Conference of Transportation Professionals, vol. 2014, pp. 769-781, Changsha, China, July 2014. 


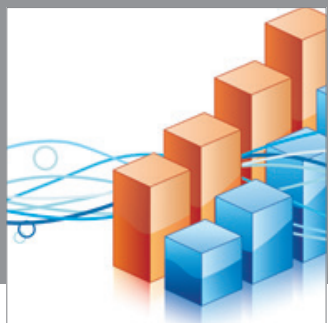

Advances in

Operations Research

mansans

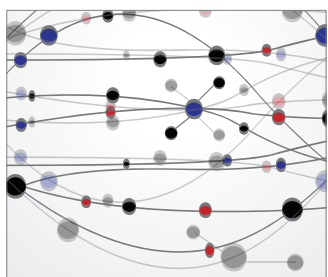

The Scientific World Journal
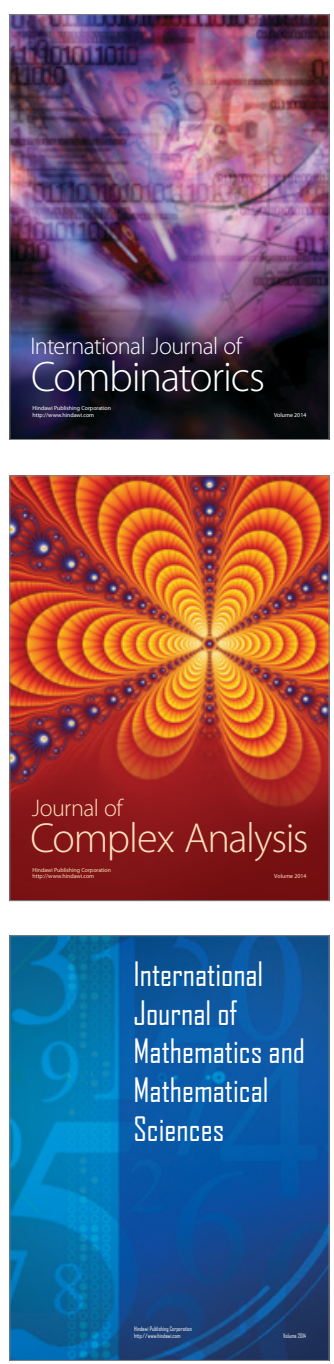
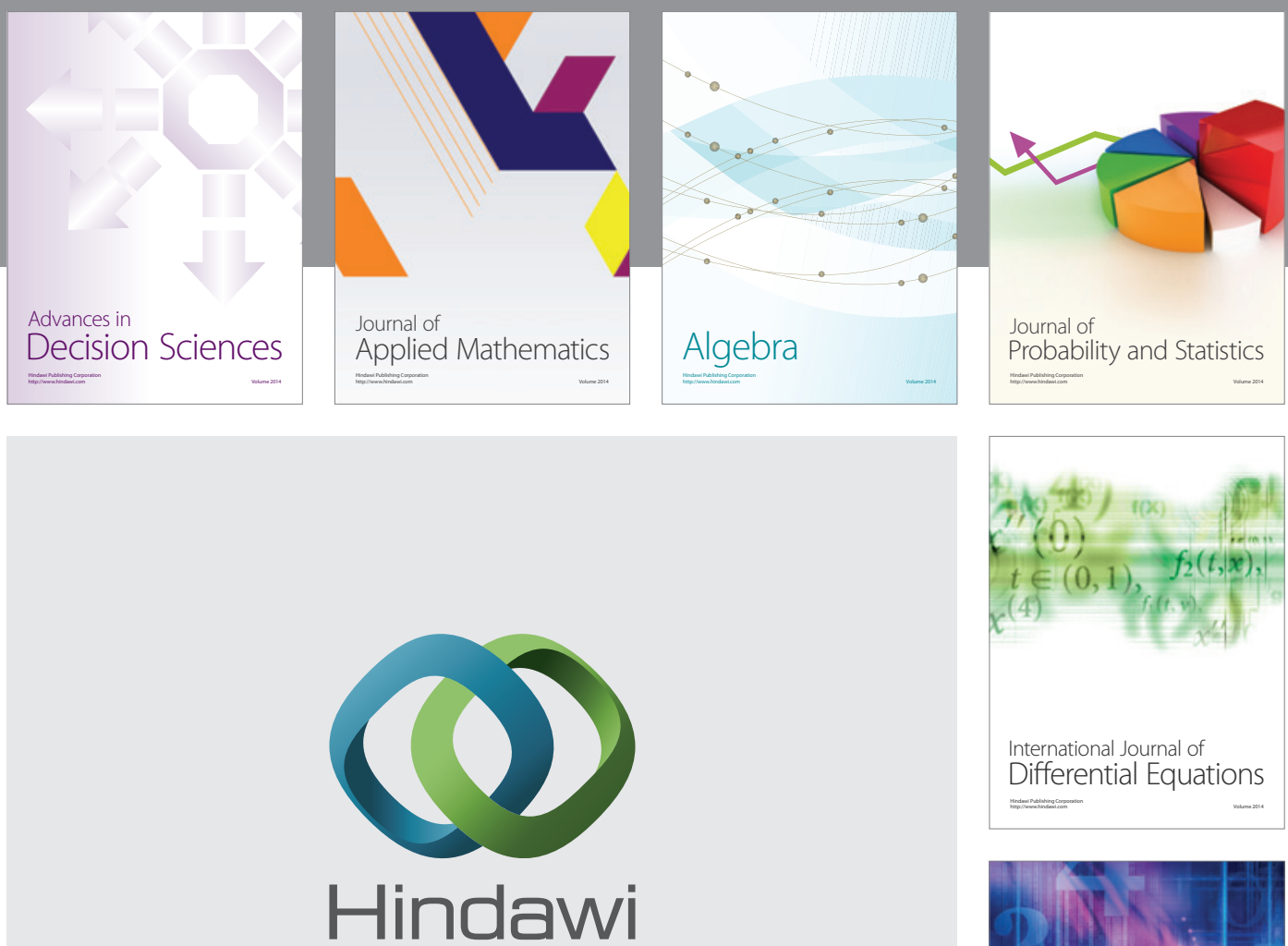

Submit your manuscripts at http://www.hindawi.com
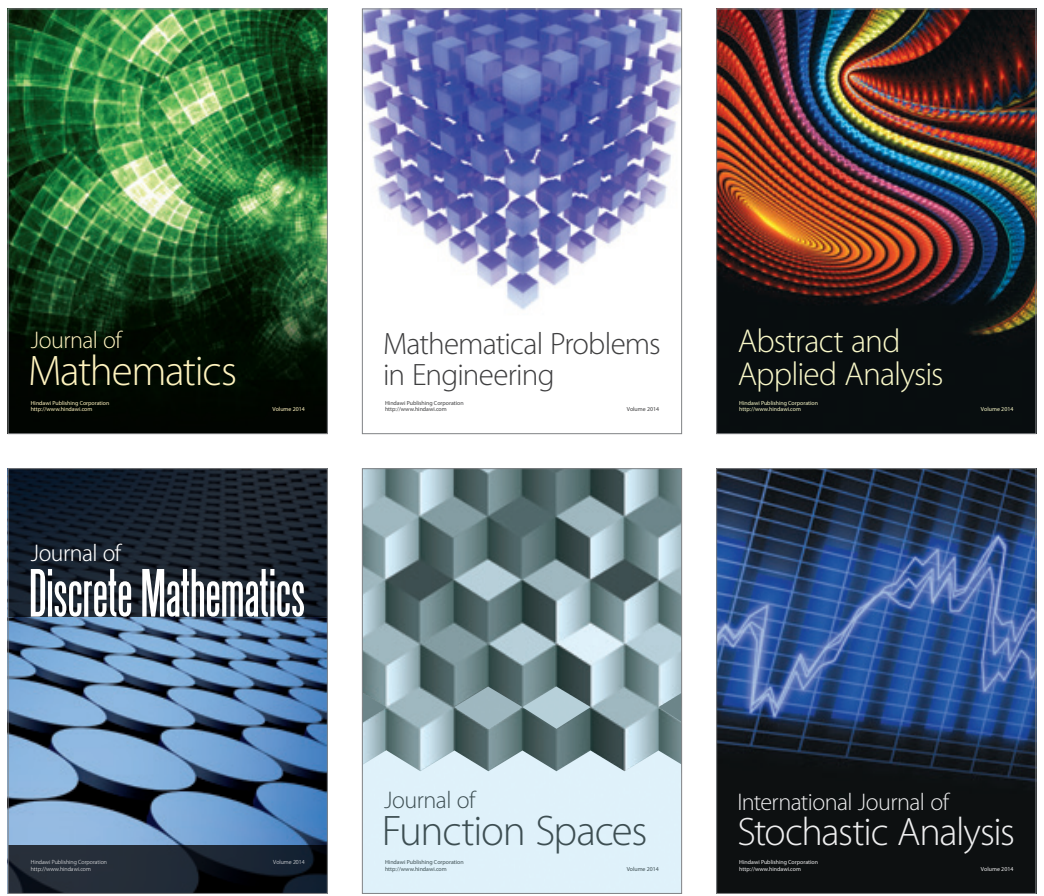

Journal of

Function Spaces

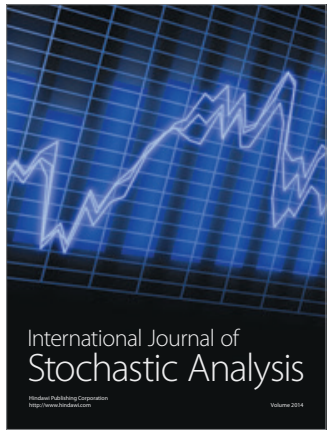

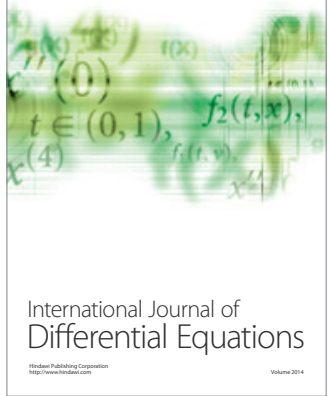
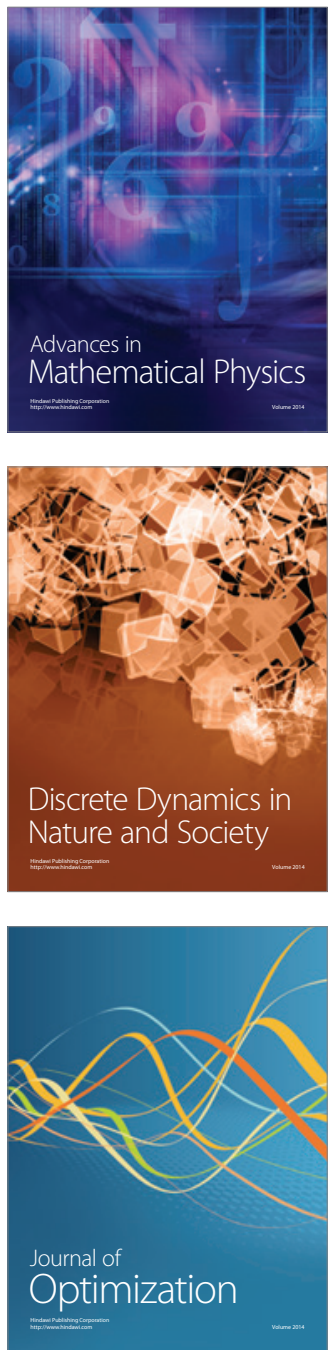